\title{
Akutneurologie im Spannungsfeld der haus- und fachärztlichen Betreuung
}

Die Neurologie ist mit etlichen Vorurteilen belastet: So galt bis vor wenigen Jahren die Aussage, dass Neurologen zwar klare Diagnosen stellen, man aber mit diesen meist nichts anfangen könne. Außerdem machte das böse Wort die Runde, dass noch nie jemand überlebt habe, weil sich der Neurologe beeilte. Diese Situation hat sich in den letzten Jahren grundlegend verändert, sodass viele neurologische Kliniken mittlerweile von der Intensivstation und Stroke unit dominiert werden und die Akutneurologie fester Bestandteil der Facharztausbildung wurde. Unter neurologischen Notfällen verstehen wir seither vor allem Schlaganfälle. Dabei wird häufig vergessen, dass die meisten neurologischen Notfälle primär nicht beim Neurologen und schon gar nicht in einer neurologischen Klinik vorgestellt werden. Diese Patienten gehen meist zuerst zum Hausarzt, stellen sich in einer Notdienstzentrale vor oder rufen den Notarzt.

Die häufigsten Notfälle dieser Art dürften neurologische Ausfälle wie Paresen und Sensibilitätsstörungen, Schwindel, Sehstörungen, starke Schmerzen und plötzliche Bewusstseinsstörungen sein. Beim heftigen Rücken- schmerz reicht das differenzialdiagnostische Spektrum vom Bandscheibenvorfall bis zum „banalen“ Hexenschuss. Die plötzliche Drehschwindelattacke ist selten Ausdruck eines Hirnstamminfarkts, sondern viel häufiger ein benigner paroxysmaler Lagerungsschwindel. Die Migräneaura ist für viele Ärzte in der Akutsituation nicht von einer TIA zu unterscheiden. Bei der heftigen Kopfschmerzattacke kann der Hausarzt ohne Bildgebung nicht entscheiden, ob es eine Subarachnoidalblutung oder eine Migräneattacke ist. Aber er muss unter medizinischen und sozioökonomischen Gesichtspunkten abwägen, wie viel und welche Zusatzdiagnostik erforderlich ist. Meist wurden die wesentlichen Entscheidungen schon getroffen, bevor der Patient vom Neurologen gesehen wird.

In diesem Heft wollen wir Ihnen exemplarisch einige unspezifische Symptome aus neurologischer Sicht präsentieren, die in der täglichen Praxis häufig sind. Dabei wählten wir absichtlich die Vorgehensweise in der täglichen Praxis statt der üblichen fachärztlichen, d. h. neurologischen Betrachtungsweise. Wir hoffen, dass das Heft auf Ihr Interesse stößt.

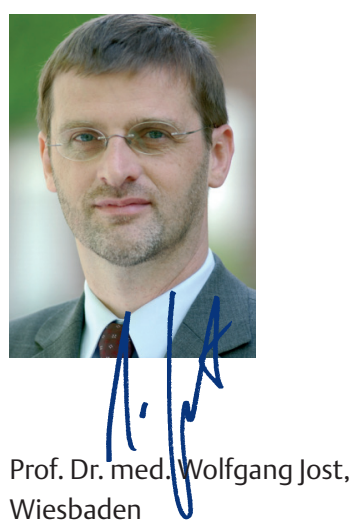

